The idea that science is a driver of prosperity is one of the few things on which the United States' bitterly divided political parties still agree. But the science funding agencies themselves are by no means immune to the second goal. The harder the cuts bite, the more those agencies will have to streamline their operations and merge or terminate programmes.

This week's budget proposal, which contains many references to "tough choices", shows that this process is already well under way. The Department of Energy (DOE), for example, wants to discontinue funding of several dozen projects that have not met their research milestones, or that seem otherwise unpromising. The National Science Foundation (NSF) is likewise cutting back on some $\$ 66$ million in lower-priority education, outreach and research programmes. The National Institutes of Health (NIH) has been ordered to pursue "new grant management policies" to increase the number of new grants by $7 \%$. And NASA is being obliged to make drastic cuts to its Mars exploration programme so as to finish building its flagship James Webb Space Telescope.

Conceivably, this process could get even more drastic. Last month, Obama asked Congress to give him the authority to consolidate and streamline agencies on his own initiative - and suggested that one early application would be to transfer the National Oceanic and Atmospheric Administration from the Department of Commerce to the Department of the Interior. If Congress were to give Obama that power, it is possible to imagine him - or some future Republican president - sending all of the NSF's science-education programmes to the Department of Education, or merging the DOE's particle and nuclear physics research into the
NSF, under the guise of making management of science more efficient.

White House officials insist that no one in the administration is even contemplating such a wholesale restructuring. But the arithmetic of the deficit is unavoidable. Individual researchers, scientific societies and
"Researchers, societies and funding agencies cannolonger afford to be purely reactive." science funding agencies can no longer afford to be purely reactive, responding to each cut as it comes along. They need to be part of the debate, thinking systematically about how programmes and even whole agencies could be restructured to make them more efficient at using the scarce funds available, and more effective at promoting the best science.

To do that, and to address the increasing demands from politicians and voters for evidence that fundamental research is useful, scientists must also find better ways to measure the effectiveness of the nation's investments in science. The usual technique is to insist that principal investigators produce more and more reports, which tends to be a waste of everyone's time. A consortium of six universities called Star Metrics, launched in 2010 and headquartered at the $\mathrm{NIH}$, has shown that it is possible to do better by using natural language processing and other tools to mine the data and reports that the agencies already collect. But even that is just a beginning. Researchers and research institutions need to help to devise still better measures - because if they don't do it themselves, politicians and others who know much less about science may very well do it for them. And who knows where that would end.

\section{On the up}

\section{The soaring incidence of diabetes is driving the United Arab Emirates' science ambitions.}

\section{I} n 1990, Dubai's desert skyline was flat. Literacy rates were low and the prevalence of diabetes was a modest $6 \%$. The effects of oil-field wealth - both good and bad — had yet to kick in. Now the skyline soars with elegant skyscrapers, among them the world's tallest, the 830 -metre-high Burj Khalifa. Literacy rates have risen with them to more than $90 \%$, thanks to the enlightened policies of the ruling families in the United Arab Emirates (UAE). Unfortunately, as the residents of the federated country settled into sedentary, well-fed lifestyles, the prevalence of diabetes also soared - to well over $20 \%$.

This is one reason why UAE science minister Sheikh Nahayan Mabarak Al Nahayan, who spoke to Nature earlier this month, sees merit in his country joining Europe's biobanking network, the Biobanking and Biomolecular Resources Research Infrastructure (BBMRI).

The BBMRI collects and shares standardized genetic and medical information on national populations. It is a long-term mega-project with a focus on complex diseases - including diabetes - that are caused by multiple genetic and environmental factors, and can be understood only by studying large numbers of people. Membership would support the UAE's focus on its principal medical problem, while building science capacity to international standards, one of its government's stated goals. For its part, the BBMRI is keen to add the emirates and its scientifically valuable population to the network.

Securing funding for the initiative won't be easy, however. The UAE comprises seven emirates, each ruled by its own royal family. Abu Dhabi is the largest by area - and, as home to most of the country's oil fields, the richest - whereas Dubai is the largest in terms of population. Between them, the royal families of these two emirates share the bulk of power in the federal government, which has a limited budget, mostly contributed by Abu Dhabi.

This complex political constellation has hindered the UAE's ambition to become a scientific force. For example, in 2008 the federal

government created the National Research Foundation (NRF) to support and encourage competitive research. Its annual budget was set at 100 million UAE dirham (US\$27 million) and it opened calls for centres of excellence and for individual investigators. Winners, identified by international peer review, were congratulated with great fanfare, but most of the promised funds for the NRF never arrived. The culture of science is new and foreign to UAE rulers, who are used to buying in whatever they need.

The process did at least provide the NRF with an effective audit of the small UAE research base. This has helped it to lobby successfully for money from industry, foundations and states on a case-by-case basis for some of the winners whose projects most visibly align with national interests, such as research on water resources. This is not how an independent research agency should operate, but positive feedback from the funded projects may eventually encourage proper funding of the NRF.

The NRF exercise also identified genetics and disease as a key research strength in the emirates, and similar lobbying is likely to see a centre of excellence established in this field. This should give hope to UAE scientists interested in participating in the BBMRI.

Those scientists met their European colleagues for first discussions earlier this month in Dubai, where they will also hold a scientific symposium in October. A formal proposal for funding will emerge from the symposium, and the UAE government would be wise to support it. UAE researchers say that the state has three natural resources: oil and gas, dates and camel milk. In decades to come, the oil and gas will run out. Membership of the BBMRI could provide a short cut in the long process of building a knowledge-based economy.

The other Gulf states share the UAE's predisposition to diabetes, as well as its dependence on oil and gas reserves. They could also benefit from joining the project, and extending the Middle Eastern population base would make the research more powerful.

Will that happen? The Gulf states tend to be very competitive. Unnerved by the Burj Khalifa, Saudi Arabia planned to build its Kingdom Tower to be 1,000 metres. And Kuwait's Mubarak al-Kabir Tower

$\rightarrow$ NATURE.COM To comment online, click on Editorials at: go.nature.com/xhunqv is proposed to be 1,001 metres. The BBMRI offers an alternative model, an umbrella under which participants cooperate and share. This is a different mind set, but one that is necessary to resolve the region's shared health problems. 